\title{
Improvement of L-ornithine production by attenuation of $\arg F$ in engineered Corynebacterium glutamicum S9114
}

\author{
Bin Zhang ${ }^{1 \dagger}$, Miao Yu ${ }^{1 \dagger}$, Ying Zhou ${ }^{1 *}$ and Bang-Ce Ye ${ }^{1,2^{*}}$
}

\begin{abstract}
L-Ornithine, a non-essential amino acid, has enormous industrial applications in food, pharmaceutical, and chemical industries. Currently, L-ornithine production is focused on microorganism fermentation using Escherichia coli or Corynebacterium glutamicum. In C. glutamicum, development of high L-ornithine producing C. glutamicum was achieved by deletion of argF, but was accompanied by growth deficiency and arginine auxotrophy. L-Arginine has been routinely added to solve this problem; however, this increases production cost and causes feedback inhibition of $\mathrm{N}$-acetyl-L-glutamate kinase activity. To avoid the drawbacks of growth disturbance due to disruption of ArgF, strategies were adopted to attenuate its expression. Firstly, ribosome binding site substitution and start codon replacement were introduced to construct recombinant $C$. glutamiucm strains, which resulted in an undesirable L-ornithine production titer. Then, we inserted a terminator $(r r n B)$ between $\operatorname{argD}$ and $\arg F$, which significantly improved L-ornithine production and relieved growth disturbance. Transcription analysis confirmed that a terminator can be used to downregulate expression of argF and simultaneously improve the transcriptional level of genes in front of argF. Using disparate terminators to attenuate expression of argF, an optimal strain (CO-9) with a T4 terminator produced $6.1 \mathrm{~g} / \mathrm{L}$ of L-ornithine, which is $42.8 \%$ higher than that produced by strain CO-1, and is 11.2 -fold higher than that of the parent $\mathrm{CO}$ strain. Insertion of terminators with gradient termination intensity can be a stable and powerful method to exert precise control of the expression level of argF in the development of L-ornithine producing strains, with potential applications in metabolic engineering and synthetic biology.
\end{abstract}

Keywords: Corynebacterium glutamicum, Terminator, Attenuation expression, L-Ornithine

\section{Introduction}

L-Ornithine, a non-essential amino acid, plays an important role in urea cycle (Jiang et al. 2013); has various applications in the treatment of diseases such as liver diseases, gyrate atrophy, and cancers in humans; and is capable of improving athletic performance (Zajac et al. 2010). Due to its numerous applications, L-ornithine high-titer production has become an important task. Currently, due to the problems of high cost, complicated operation, and environmental harm, L-ornithine production by chemical

\footnotetext{
*Correspondence: zhouying@ecust.edu.cn; bcye@ecust.edu.cn

${ }^{\dagger}$ Bin Zhang and Miao Yu contributed equally to this work

${ }^{1}$ Laboratory of Biosystems and Microanalysis, State Key Laboratory

of Bioreactor Engineering, East China University of Science

and Technology, Shanghai 200237, China

Full list of author information is available at the end of the article
}

means has generally been replaced by fermentation using Escherichia coli or Corynebacterium glutamicum (Hwang and Cho 2014; Jensen et al. 2015; Lee et al. 2010). L-Ornithine synthesis from L-glutamate consists of four enzymatic reactions, which involve the $\arg C J B D F R$ operon in C. glutamicum (Fig. 1) (Kim et al. 2015). Among them, ornithine carbamoyl transferase (OTC), encoded by $\operatorname{argF}$, is the key enzyme for converting L-ornithine to L-citrulline. Deletion of argF leads to L-ornithine accumulation and simultaneously, makes the strain auxotrophic for L-arginine (Lee and Cho 2006). Although addition of arginine into the medium can recover cell growth, it also leads to additional costs and feedback regulation. Thus, attenuation of expression of $\operatorname{argF}$ is a potential strategy for balancing L-ornithine production and cell growth. 


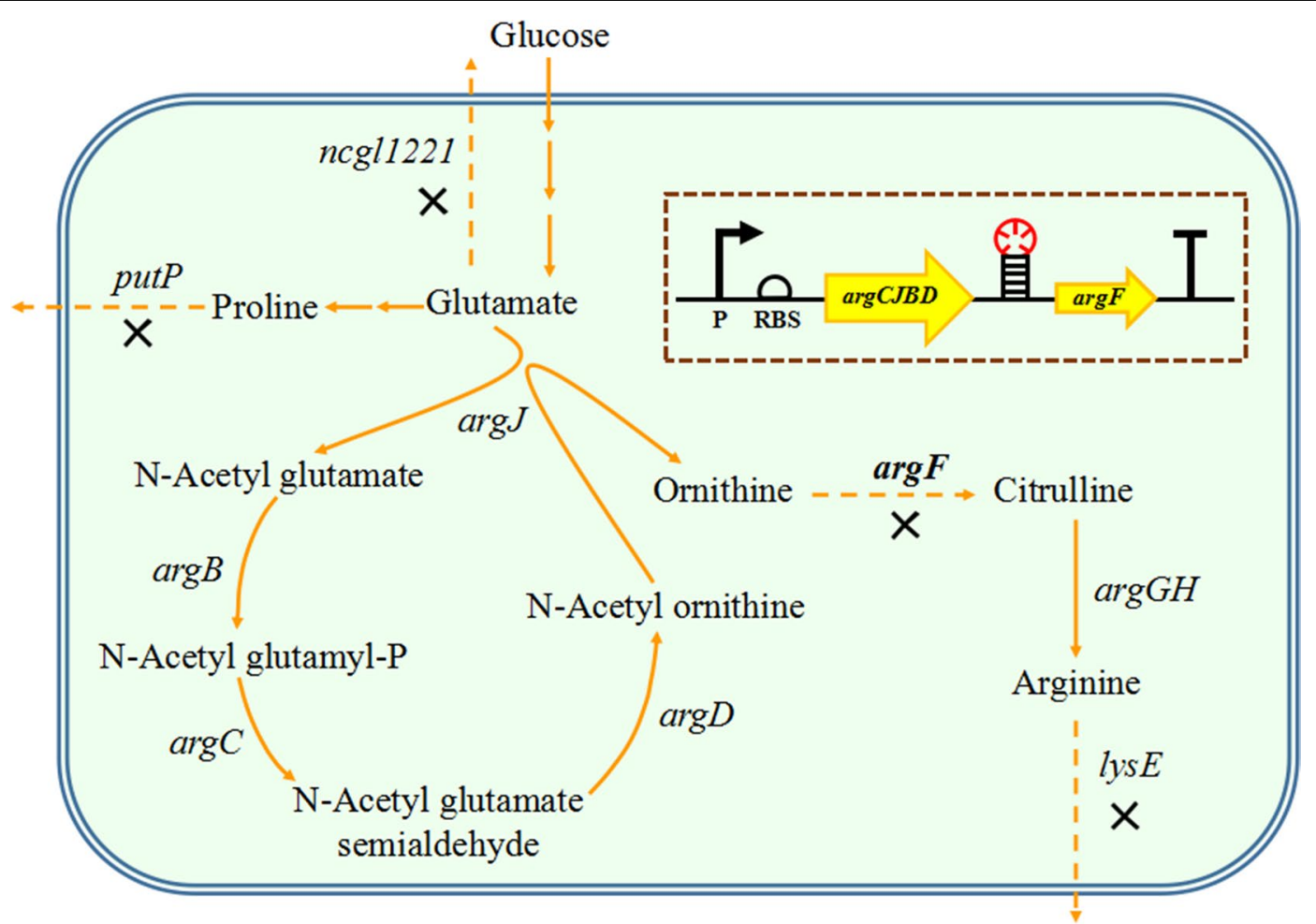

Fig. 1 Metabolic pathways associated with ornithine biosynthesis in C. glutamicum and the metabolic engineering strategies of ornithine production. Yellow boxes represent the targeted modifications of the genes and the location of terminators. Products of the genes are: $\arg B$ acetylglutamate kinase, $\arg \mathrm{C} \mathrm{N}$-acetyl-gamma-glutamylphosphate reductase, $\arg \mathrm{D}$ acetylornithine aminotransferase, argF ornithine carbamoyltransferase, arg $\mathrm{G}$ arginine succinate synthase, $\arg \mathrm{H}$ arginosuccinase, $\mathrm{arg}$ J ornithine acetyltransferase/ $\mathrm{N}$-acetylglutamate synthase, lysE cncoding lysine/arginine transporter, putP encoding L-proline transporter, ncgl1221 encoding glutamate transporter. Multiplication sign represents the deletion of relevant gene

To attenuate the expression of target genes, numerous strategies such as RBS modification, translational start codon exchange, promoter replacement, and RNA interference have been carried out and widely applied in the past decades (Man et al. 2016; Shen et al. 2017). RBS and changing of the translational start codon of the enzyme-coding genes directly affect the translation of the corresponding enzyme and have been applied in pathway engineering. Promoter replacement and RNA interference were useful strategies for regulation of the transcription process. Transcription is a process that includes recruitment of RNA polymerase (RNAP) to a promoter, synthesis of mRNA, and dissociation of RNAP at a terminator sequence. The terminator is an important component of the transcription process, which is known to be crucial for protein expression (Nakamura et al. 2015).

In this study, a C. glutamicum S9114 mutant strain, with deletion of $n c g l 1221$, lysE, putP, and $\operatorname{argR}$, was selected as the parent strain for the attenuation of $\arg F$. By analysis of L-ornithine production, cell growth, and the relative transcription level of the genes involved in the L-ornithine synthesis pathway, we confirmed that terminators can be used to downregulate $\arg F$ expression and to improve L-ornithine production.

\section{Materials and methods}

\section{Strains and growth conditions}

The strains and plasmids used in this work are listed in Table 1. E. coli DH5 $\alpha$ was used for DNA manipulation and plasmid construction. For recombinant DNA work, E. coli $\mathrm{DH} 5 \alpha$ was cultivated at $37{ }^{\circ} \mathrm{C}$ in $\mathrm{LB}$ medium. If needed, kanamycin $(50 \mathrm{mg} / \mathrm{L}$ for $E$. coli $\mathrm{DH} 5 \alpha$ or $25 \mathrm{mg} / \mathrm{L}$ for C. glutamicum strains) was added to the medium. For L-ornithine production in C. glutamicum, a seed culture was prepared by inoculating cells into the seed medium [30 g glucose, $10 \mathrm{~g}$ yeast extract, $10 \mathrm{~g}$ corn steep liquor, $15 \mathrm{~g}\left(\mathrm{NH}_{4}\right)_{2} \mathrm{SO}_{4}, 2.5 \mathrm{~g} \mathrm{MgSO}_{4} \cdot 7 \mathrm{H}_{2} \mathrm{O}, 1 \mathrm{~g} \mathrm{KH}_{2} \mathrm{PO}_{4}, 0.5 \mathrm{~g}$ $\mathrm{K}_{2} \mathrm{HPO}_{4}, 0.5 \mathrm{~g} \mathrm{Na}_{2} \mathrm{HPO}_{4}$, and $10 \mathrm{~g} \mathrm{CaCO}_{3}$ per liter] and allowing them to grow for $11 \mathrm{~h}$. Then, the seed culture was inoculated into $25 \mathrm{~mL}$ of the fermentation medium and the initial $\mathrm{OD}_{600}$ was adjusted to 1 . Each liter of the fermentation medium consisted of $100 \mathrm{~g}$ glucose, $20 \mathrm{~g}$ corn steep liquor, $50 \mathrm{~g}\left(\mathrm{NH}_{4}\right)_{2} \mathrm{SO}_{4}, 2.5 \mathrm{~g} \mathrm{MgSO} 4 \cdot 7 \mathrm{H}_{2} \mathrm{O}$, $1 \mathrm{~g} \mathrm{KH}_{2} \mathrm{PO}_{4}, 0.5 \mathrm{~g} \mathrm{~K}_{2} \mathrm{HPO}_{4}, 0.5 \mathrm{~g} \mathrm{Na}_{2} \mathrm{HPO}_{4}, 0.02 \mathrm{~g}$ $\mathrm{FeSO}_{4} \cdot 7 \mathrm{H}_{2} \mathrm{O}, 0.02 \mathrm{~g} \mathrm{MnSO}_{4} \cdot 4 \mathrm{H}_{2} \mathrm{O}$, and $10 \mathrm{~g} \mathrm{CaCO}_{3}$ 
Table 1 Strains and plasmids used in this study

\section{Strains and plasmids Relevant characteristics}

Strains

C. glutamicum $\mathrm{S} 9114$

$\mathrm{CO}$

$\mathrm{CO}-1$

$\mathrm{CO}-2$

$\mathrm{CO}-3$

$\mathrm{CO}-4$

$\mathrm{CO}-5$

$\mathrm{CO}-6$

$\mathrm{CO}-7$

$\mathrm{CO}-8$

$\mathrm{CO}-9$

CO-10

CO-11

$\mathrm{CO}-12$

CO-13

CO-14

CO-15

CO-16

CO-17

CO-18

CO-19

CO-20

$\mathrm{CO}-21$

CO-22

CO-23

Plasmids

pK18mobsacB

pXMJ19

pK18- $\triangle$ argF

pK18-argF10-G

pK18-argF50-G

pK18-argF100-G

pK18-argF500-G

pK18-T1

pK18-T2

pK18-T3

pK18-T4

pK18-T5

pK18-T6

pK18-T7

pK18-T8

pK18-T9

PK18-T10

pK18-T11

Clone host strain replacement with GTG replacement with GTG replacement with GTG replacement with GTG ndustrial strain for glutamate production

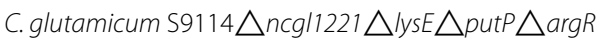

$\mathrm{CO}$ derivative with in-frame deletion of $\arg \mathrm{F}$

$\mathrm{CO}$ derivative with replacement of RBS10 and $\mathrm{A} 1 \mathrm{G}$ in $\arg F$

$\mathrm{CO}$ derivative with replacement of RBS50 and start A1G in argF

$\mathrm{CO}$ derivative with replacement of RBS100 A1G in argF

CO derivative with replacement of RBS500 and A1G in argF

$\mathrm{CO}$ derivative with insertion of terminator $\mathrm{T} 1 \mathrm{in}$ front of $\arg \mathrm{F}$

$\mathrm{CO}$ derivative with insertion of terminator $\mathrm{T} 2 \mathrm{in}$ front of $\arg \mathrm{F}$

$\mathrm{CO}$ derivative with insertion of terminator $\mathrm{T} 3 \mathrm{in}$ front of argF

$\mathrm{CO}$ derivative with insertion of terminator $\mathrm{T} 4 \mathrm{in}$ front of arg $\mathrm{F}$

$\mathrm{CO}$ derivative with insertion of terminator $\mathrm{T} 5$ in front of arg $\mathrm{F}$

$\mathrm{CO}$ derivative with insertion of terminator T6 in front of argF

$\mathrm{CO}$ derivative with insertion of terminator T7 in front of argF

$\mathrm{CO}$ derivative with insertion of terminator $\mathrm{T} 8 \mathrm{in}$ front of arg $\mathrm{F}$

$\mathrm{CO}$ derivative with insertion of terminator T9 in front of argF

$\mathrm{CO}$ derivative with insertion of terminator T10 in front of argF

$\mathrm{CO}$ derivative with insertion of terminator T11 in front of argF

$\mathrm{CO}$ derivative with insertion of terminator T12 in front of $\arg F$

$\mathrm{CO}$ derivative with insertion of terminator T13 in front of argF

$\mathrm{CO}$ derivative with insertion of terminator T14 in front of argF

$\mathrm{CO}$ derivative with insertion of terminator T15 in front of argF

$\mathrm{CO}$ derivative with insertion of terminator T16 in front of $\operatorname{argF}$

$\mathrm{CO}$ derivative with insertion of terminator T17 in front of $\arg F$

$\mathrm{CO}$ derivative with insertion of terminator T18 in front of argF

Mobilizable vector, allows for selection of double crossover in C. glutamicum, $\mathrm{Km}^{\mathrm{R}}$, sacB

A shuttle expression vector, $\mathrm{Cm}^{\mathrm{R}}$

A derivative of pK18mobsacB, harboring $\triangle$ argF fragment

A derivative of pK18mobsacB, harboring the fragment of $\arg F(10 \mathrm{au}$ ) RBS change and start codon

A derivative of pK18mobsacB, harboring the fragment of $\operatorname{argF}(50 \mathrm{au}$ ) RBS change and start codon

A derivative of pK18mobsacB, harboring the fragment of $\operatorname{argF}(100 \mathrm{au}$ ) RBS change and start codon

A derivative of pK18mobsacB, harboring the fragment of $\operatorname{argF}(500 \mathrm{au}$ ) RBS change and start codon

A derivative of pK18mobsacB, harboring the fragment of inserting $T 1$ terminator in front of arg $F$

A derivative of pK18mobsacB, harboring the fragment of inserting $T 2$ terminator in front of arg $F$

A derivative of $\mathrm{pK} 18$ mobsacB, harboring the fragment of inserting $\mathrm{T} 3$ terminator in front of arg $F$

A derivative of pK18mobsacB, harboring the fragment of inserting $T 4$ terminator in front of arg $F$

A derivative of pK18mobsac $B$, harboring the fragment of inserting $T 5$ terminator in front of arg $F$

A derivative of $\mathrm{pK} 18$ mobsacB, harboring the fragment of inserting $T 6$ terminator in front of arg $F$

A derivative of $\mathrm{pK} 18$ mobs $a c B$, harboring the fragment of inserting $T 7$ terminator in front of arg $F$

A derivative of $\mathrm{pK} 18$ mobs $a c B$, harboring the fragment of inserting $T 8$ terminator in front of arg $F$

A derivative of pK18mobsacB, harboring the fragment of inserting T9 terminator in front of arg $F$

A derivative of pK 18 mobsacB, harboring the fragment of inserting $\mathrm{T} 10$ terminator in front of arg $F$

A derivative of pK18mobsacB, harboring the fragment of inserting $T 11$ terminator in front of arg $F$
Sources or references

Transgen

Mei et al. (2016)

Our lab

This study

This study

This study

This study

This study

This study

This study

This study

This study

This study

This study

This study

This study

This study

This study

This study

This study

This study

This study

This study

This study

This study

This study

Zhang et al. (2015)

Jakoby et al. (1999)

This study

This study

This study

This study

This study

This study

This study

This study

This study

This study

This study

This study

This study

This study

This study

This study 
Table 1 continued

\begin{tabular}{llll}
\hline Strains and plasmids & Relevant characteristics & Sources or references \\
\hline pK18-T12 & A derivative of pK18mobsacB, harboring the fragment of inserting T12 terminator in front of argF & This study \\
pK18-T13 & A derivative of pK18mobsacB, harboring the fragment of inserting T13 terminator in front of arg $F$ & This study \\
pK18-T14 & A derivative of pK18mobsacB, harboring the fragment of inserting T14 terminator in front of argF & This study \\
pK18-T15 & A derivative of pK18mobsacB, harboring the fragment of inserting T15 terminator in front of argF & This study \\
pK18-T16 & A derivative of pK18mobsacB, harboring the fragment of inserting T16 terminator in front of argF & This study \\
pK18-T17 & A derivative of pK18mobsacB, harboring the fragment of inserting T17 terminator in front of argF & This study \\
pK18-T18 & A derivative of pK18mobsacB, harboring the fragment of inserting T18 terminator in front of argF & This study \\
\hline
\end{tabular}

Superscript " $\mathrm{R}$ " indicates resistance to the following antibiotics: $\mathrm{Km}$ kanamycin, $\mathrm{Cm}$ chloramphenicol

(Zhang et al. 2017). For both media, the initial $\mathrm{pH}$ was adjusted to 7.0. All of the cultures were grown at $32{ }^{\circ} \mathrm{C}$ and $250 \mathrm{rpm}$ on a rotary shaker, and samples were taken to monitor the $\mathrm{L}$-ornithine production and biomass.

\section{Construction of recombinant plasmids and strains}

All recombinant strains were derived from C. glutamicum S9114 (Mei et al. 2016), which also stored at Shanghai Industrial Institute of Microorganisms (SIIM), Shanghai, China with the storage number as SIIM B460 and China Center of Industrial Culture Collection (CICC) with the registration number of CICC 20935. The homologous $s a c B$ recombination system was used to introduce modulations into the chromosome as described previously (Kim et al. 2015; Niebisch and Bott 2001). To disrupt argF in C. glutamicum, the upstream region and downstream region of $\arg F$ were PCR amplified and cloned into the HindIII/XbaI sites of pK18mob$s a c B$ by Gibson assembly to generate the recombinant plasmid $\mathrm{pK} 18-\triangle \arg F$. In addition, for RBS replacement in the chromosome, the recombinant plasmids with upstream and downstream fragments, an artificial, synthetic RBS, and A1G replacement were also PCR amplified and cloned into pK18mobsacB. Synthetic RBSs with different translation initiation strengths were designed by an RBS Calculator (Tian and Salis 2015) (https://www. denovodna.com/software/doLogin) and inserted among the homologous arms by overlap PCR. The sequences of the synthetic RBSs are listed in Additional file 1: Table S2. Moreover, for insertion of the terminator in front of $\operatorname{argF}$, terminators derived from a previous study (Chen et al. 2013) were added between the upstream and downstream sequences by overlap PCR and then cloned into plasmid pK18mobsacB. All of the recombinant plasmids were transformed into C. glutamicum cells by electroporation. After two rounds of homologous recombination, engineered C. glutamicum with the corresponding chromosomal modifications were verified by PCR. All of the primers used in this study are listed in Additional file 1: Table S1.

\section{Quantitative real-time (RT) PCR}

RT-PCR assays were conducted as described in our previous study (Liao et al. 2015). Total RNA from C. $g l u$ tamicum cells was extracted during the exponential phase using an RNA extraction kit (Tiangen Biotech Co., Ltd., Beijing, China), and the RNA concentration was determined by a microplate reader (BioTek Instruments, Winooski, VT, USA). The cDNA was synthesized using the PrimeScript RT Reagent Kit with gDNA Eraser (TaKaRa, Shiga, Japan) and a Touch Real-Time PCR System (Bio-Rad Hercules, CA, USA), using the SYBR Premix Ex TaqTM II (TaKaRa, Shiga, Japan) on a Bio-Rad CFX96. cDNA (100 ng) was used as template. The PCR conditions were: $94{ }^{\circ} \mathrm{C}$ for $30 \mathrm{~min}$, then 45 cycles at $94{ }^{\circ} \mathrm{C}$ for $5 \mathrm{~s}$ and $60^{\circ} \mathrm{C}$ for $30 \mathrm{~min}$. The data were normalized as per the $16 \mathrm{~S}$ rRNA expression. The primers for RT-PCR are presented in the Additional file 1.

\section{Analytical procedures}

Cell growth was monitored by measuring the optical density of the culture at $600 \mathrm{~nm}\left(\mathrm{OD}_{600}\right)$ using an spectrophotometer, after dilution of the culture with $0.125 \mathrm{~mol} / \mathrm{L}$ $\mathrm{HCl}$ to dissolve $\mathrm{CaCO}_{3}$ (Hao et al. 2016). The production of L-ornithine was determined by ninhydrin colorimetry, as described previously (Chinard 1952).

\section{Results \\ L-Ornithine accumulation and cell growth deficiency led by deletion of $\operatorname{argF}$}

$A r g F$, encoding ornithine carbamoyl transferase (OTC), plays a critical role in the biodegradation of L-ornithine. To accumulate L-ornithine, $\operatorname{argF}$ was deleted in strain $\mathrm{CO}$, resulting in strain $\mathrm{CO}-1$. Then, strain $\mathrm{CO}-1$ was cultivated in a shaking flask, and the fermentation data revealed that $4.27 \mathrm{~g} / \mathrm{L}$ of L-ornithine was detected in the broth after $48 \mathrm{~h}$ of incubation. However, the cell growth of CO-1 was $22 \%$ lower than that of the parent $\mathrm{CO}$ strain (Fig. 2). Recovery of cell growth by the addition of L-arginine into the broth has been frequently used as a strategy to relieve the growth disturbance caused by argF deletion. 

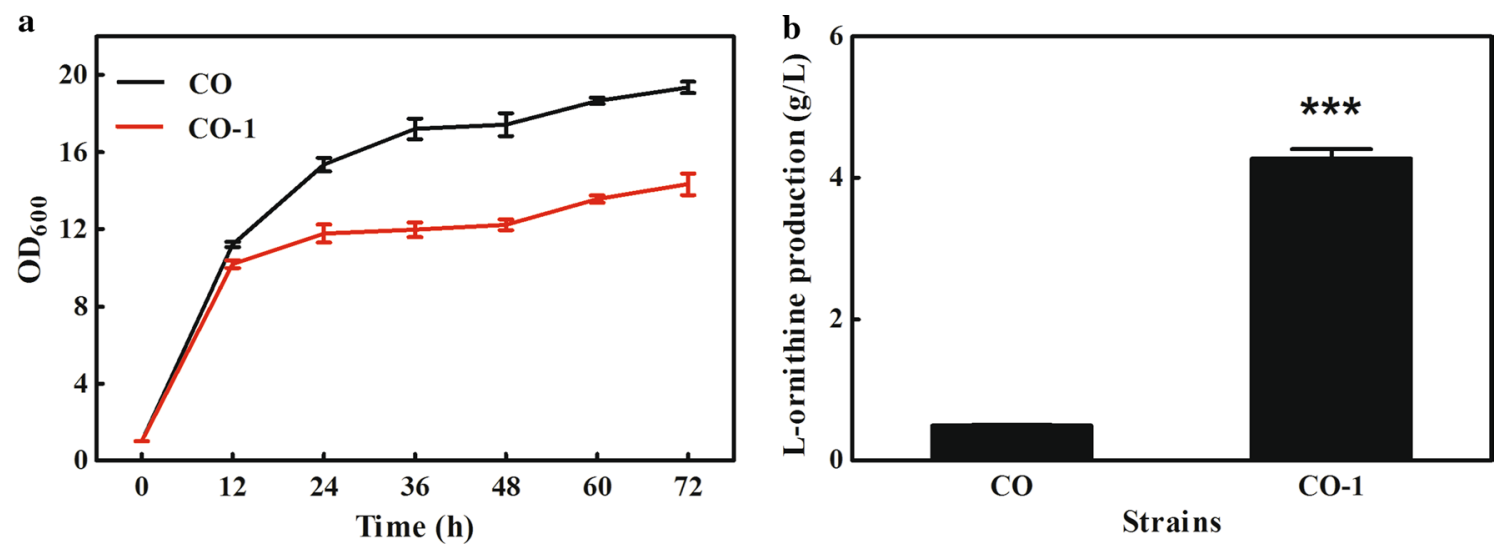

Fig. 2 Cell growth and L-ornithine production of the strains CO and CO-1. a Growth curves under $72 \mathrm{~h}$ in shake flasks. b L-Ornithine production at $48 \mathrm{~h}$ of incubation. The error bars represent the standard deviation of samples. ${ }^{* *} \mathrm{p} \leq 0.001$

Therefore, to relieve the growth deficiency, an L-arginine addition experiment was performed. As shown in Fig. 3a, growth of strain CO-1 gradually recovered with the supplementation of L-arginine, which indicated that the growth disturbance was caused by deficiency of L-arginine. However, no significant changes in L-ornithine production were observed after addition of $\mathrm{L}$-arginine in the $\mathrm{CO}$ strain, while the L-ornithine production titer of strain $\mathrm{CO}-1$ was reduced. As shown in Fig. 3b, when L-arginine was added up to a concentration of $5 \mathrm{~g} / \mathrm{L}$, the L-ornithine production of strain CO-1 dropped from 4.27 to $0.61 \mathrm{~g} / \mathrm{L}$. These results suggested that deletion of $\operatorname{argF}$ in the engineered strain $\mathrm{CO}-1$ led to growth deficiency, which was relieved by L-arginine supplementation, but addition of $\mathrm{L}$-arginine into the fermentation broth inhibited L-ornithine production in this strain.
RBS optimization was undesirable for attenuating the expression of $\arg \mathrm{F}$ to promote L-ornithine production Based on the results of the $\mathrm{L}$-arginine addition experiments and after taking the cost into consideration, we found that supplementation of the medium with $\mathrm{L}$-arginine was unsuitable for relieving the growth disturbance brought by arginine auxotroph. Then, inspired by a previous study that fine-tuned ornithine transcarbamoylase activity using a plasmid addiction system to improve putrescine production (Schneider et al. 2012), we intended to downregulate $\arg F$ expression and explore an appropriate expression model that balanced the cell growth and L-ornithine production. Thus, RBS substitution and start codon replacement were carried out to attenuate the expression of $\operatorname{argF}$. The predicted natural RBS strength of $\operatorname{argF}$ is $35364.4 \mathrm{au}$. Therefore, we replaced the natural RBS with weaker RBSs with different initial translation strengths $(10,50,100$, and $500 \mathrm{au})$, and
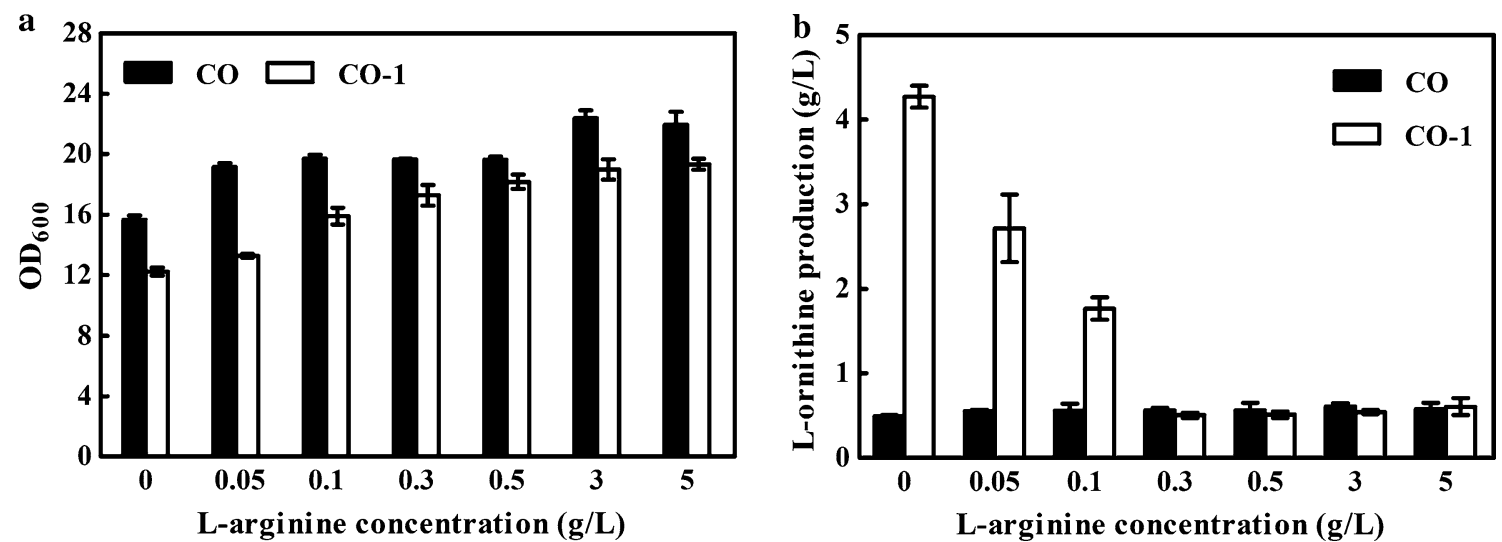

Fig. 3 Fermentation of the strains $\mathrm{CO}$ and CO-1 with addition of disparate L-arginine concentration into the medium. a Cell growth. $\mathbf{b} \mathrm{L}-\mathrm{Ornithine}$ production at $48 \mathrm{~h}$ in shake flasks 
the start codon ATG was replaced with GTG, generating strains $\mathrm{CO}-2$, $\mathrm{CO}-3, \mathrm{CO}-4$, and $\mathrm{CO}-5$. As shown in Fig. 4, $\mathrm{L}$-ornithine production by these strains showed obvious improvement, compared to the $\mathrm{CO}$ strain, but the highest titer produced by strain CO-4 was only $1 \mathrm{~g} / \mathrm{L}$, which was three-fold lower than that produced by CO-1 $(4.27 \mathrm{~g} / \mathrm{L})$. It was concluded that attenuating the expression of $\operatorname{argF}$ through RBS optimization and start codon replacement was undesirable for L-ornithine accumulation.

\section{Improvement of L-ornithine production by insertion of a terminator in front of $a r g F$}

$A r g R$, a negative regulatory protein of the $\arg C J B D F R$ operon, was disrupted previously, which led to a higher transcription level of $\operatorname{argCJBDF}$ in $\mathrm{CO}$. The increased transcription level of $\arg F$ might explain why replacement of the RBS and start codon could not lead to the desired $\mathrm{L}$-ornithine production level. Therefore, we continued to insert a terminator ( $r r n B$ from plasmid pXMJ19) before $\arg F$ to reduce the transcription level of $\arg F$, generating strain CO-6. Interestingly, after $48 \mathrm{~h}$ of shake flask fermentation, strain CO-6 produced $5.53 \mathrm{~g} / \mathrm{L}$ of L-ornithine, which was $29.5 \%$ higher than the production level of the $\operatorname{argF}$ deletion strain CO-1 (4.27 g/L) (Fig. 5a). Cell growth also increased from an $\mathrm{OD}_{600}$ of 12.23 to an $\mathrm{OD}_{600}$ of 13.42. To investigate the mechanism behind this phenomenon, the transcription levels of the genes involved in L-ornithine synthesis were analyzed. The expression level of $\operatorname{argF}$ in strain CO-1 dropped to zero. Compared with the parent strain $\mathrm{CO}$, the relative transcriptional level of $\operatorname{argF}$ in strain CO-6 was reduced to 47\%. For the terminator upstream of the genes, the expression levels of
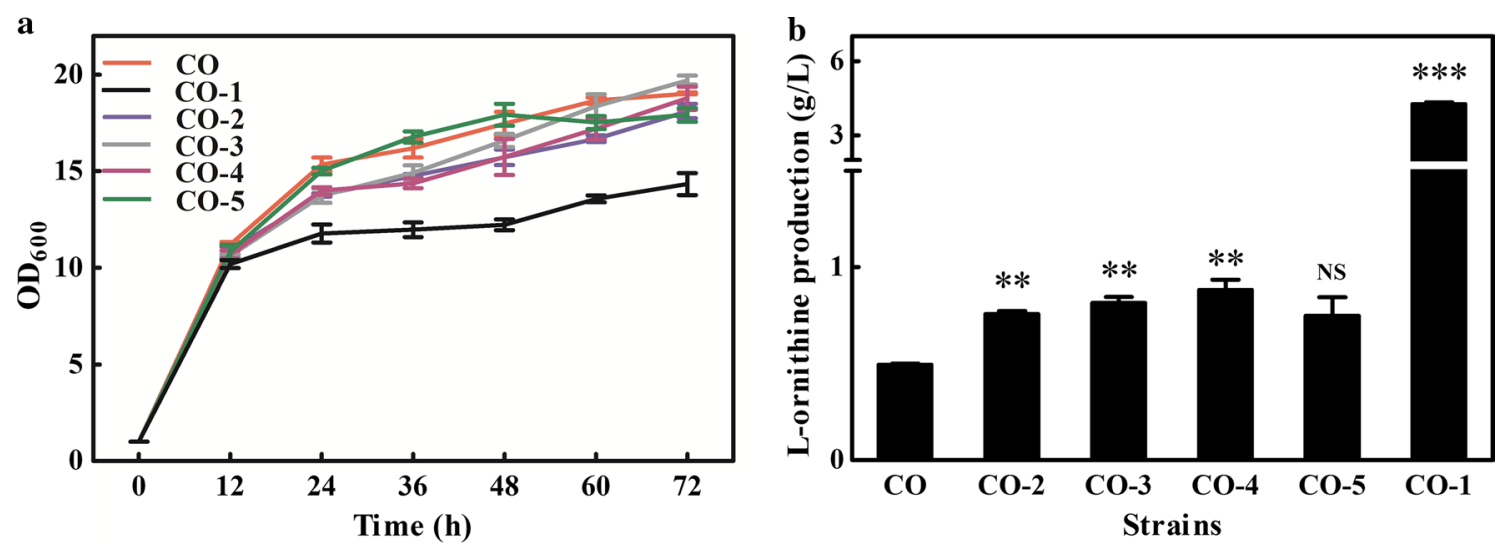

Fig. 4 Cell growth and L-ornithine production of the strains with changing RBS site and replacing start codon of argF. $\mathbf{a}$ Growth curves under $72 \mathrm{~h}$ of Shake flask culture. $\mathbf{b} \mathrm{L}-$ Ornithine production at $48 \mathrm{~h}$ of incubation. The error bars represent the standard deviation of samples. Compared with the controlling strain CO. NS means not significant. ${ }^{* *} p \leq 0.05$ and ${ }^{* *} p \leq 0.001$
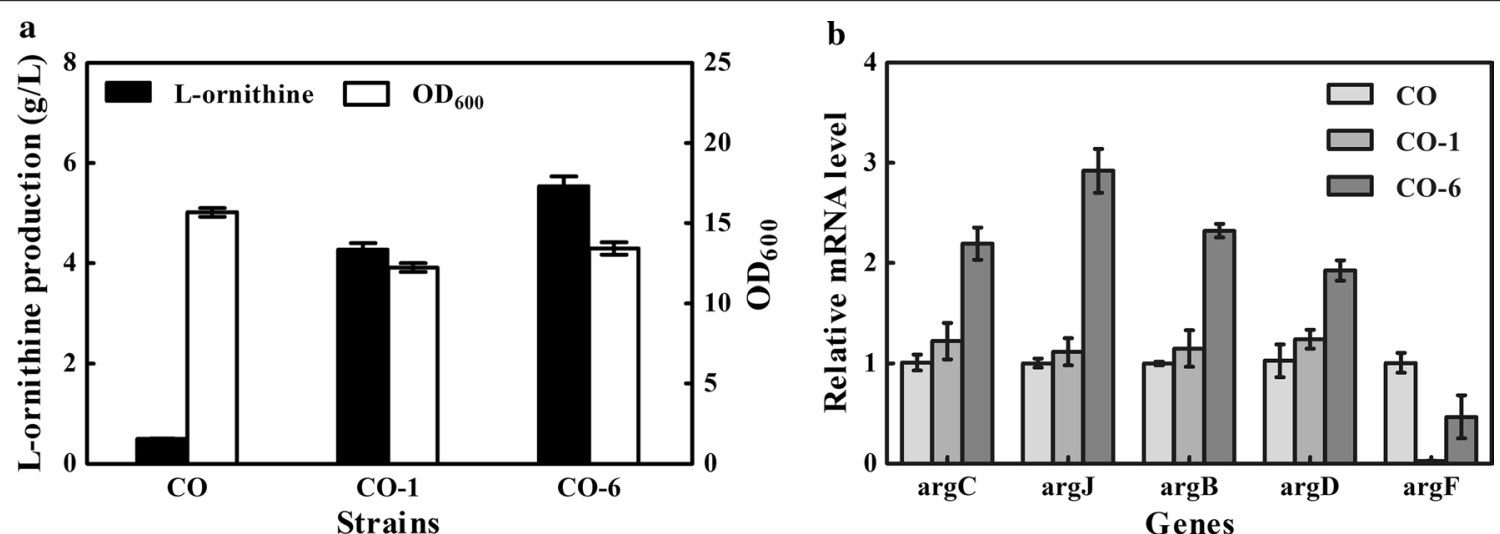

Fig. 5 Fermentation data and relative transcription levels of selected genes of the strains CO, CO-1 and CO-6. a Cell growth and L-ornithine production of the strains. $\mathbf{b}$ Comparison of the transcriptional levels of L-ornithine biosynthesis genes 
$\arg C, \operatorname{argJ}, \arg B$, and $\arg D$ in strain CO-6 increased 2.17-, 2.91-, 2.32-, and 1.88-fold, respectively, while no corresponding changes were detected in strain CO-1 (Fig. 5b). These results suggested that increased expression of the $\arg C J B D$ operon stimulated L-ornithine production, and the leaky expression of $\arg F$ contributed to the improvement of cell growth.

\section{Improvement of L-ornithine production by optimizing the terminators}

In order to increase L-ornithine production with an improvement in cell growth, seventeen terminators discovered by Chen et al. (Chen et al. 2013) (Additional file 1: Table S3) with different termination strengths were selected and inserted into the chromosome of strain $\mathrm{CO}$, resulting in 17 mutant strains (CO-7 to $\mathrm{CO}-23$ ). Fermentation experiments were carried out to evaluate the effect of these modifications on L-ornithine production and cell growth. As shown in Fig. 6a, the yield of
L-ornithine, produced by strain CO-9, was $6.1 \mathrm{~g} / \mathrm{L}$, which was $42.8 \%$ higher than that by strain $\mathrm{CO}-1(4.27 \mathrm{~g} / \mathrm{L})$. Compared with CO-1, the cell growth of CO-9 also improved from $\mathrm{OD}_{600}=12.2$ to $\mathrm{OD}_{600}=13.5$, after $48 \mathrm{~h}$ of incubation. The argF expression levels of the recombinant strains $\mathrm{CO}-8, \mathrm{CO}-9$, and $\mathrm{CO}-25$, with terminator strengths of 239.91, 216.60, and 10.94, were 34, 35, and $65 \%$, respectively, indicating that the expression level of $\arg F$ decreased with improved terminator strength. In addition, insertion of a terminator in front of $\arg F$ was an efficient strategy for improving L-ornithine production, by slightly relieving the growth disturbance, by blocking L-ornithine degradation. Moreover, these results also suggested that addition of a terminator could act as a reliable method for controlling gene expression and are a potential genetic engineering tool for C. glutamicum.

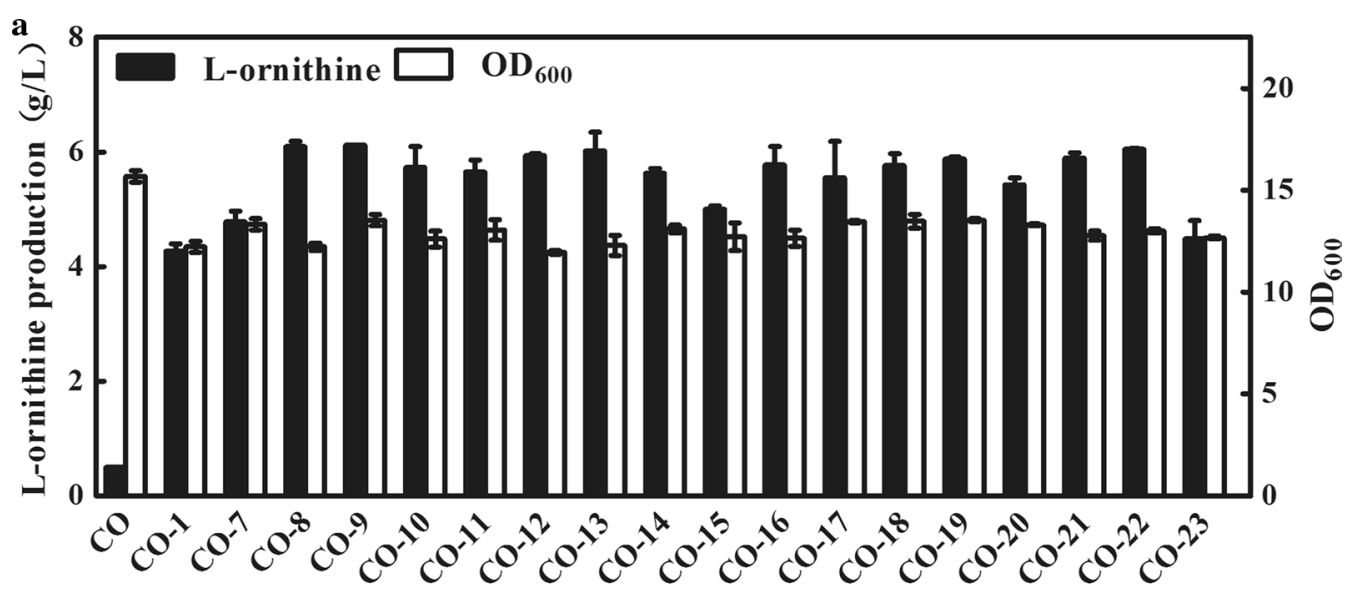

Strains

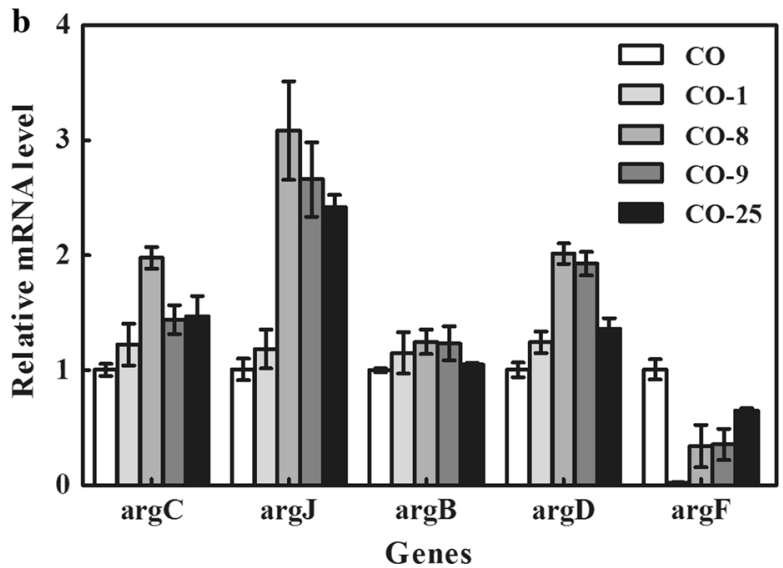

Fig. 6 Fermentation data and relative transcription levels of selected genes in the strains with terminators at $48 \mathrm{~h}$ in shake flasks. a Cell growth and L-ornithine production of the strains. b Comparison of the transcriptional levels of L-ornithine biosynthesis genes 


\section{Discussion}

Based on our current knowledge, gene knockout is an effective strategy in genetic engineering for developing high target-compound producing strains. However, deletion of growth-coupled genes can induce some undesired results, such as a growth deficiency or extra nutritional requirements, which are undesirable for industrial fermentation. The same phenomenon of biomass deficiency caused by deletion, $\arg F$ specifically here, was observed in the study on $\mathrm{L}$-arginine auxotroph in engineered $C$. glutamicum S9114, which employed a common strategy used in the construction of engineered strains for L-ornithine production (Hwang et al. 2008; Zhang et al. 2017). However, addition of $\mathrm{L}$-arginine caused feedback inhibition of $\mathrm{N}$-acetyl-L-glutamate kinase (NAGK) enzyme activity, which reduced the yield of L-ornithine, consistent with the results observed in a previous study (Kim et al. 2015). This problem was solved by overexpression of an anti-feedback inhibited NAGK from C. glutamicum ATCC 21831; however, the cost of L-arginine addition and the genetic instability from using a plasmid hampered its industrial application in L-ornithine production. Thus, to address these problems, attenuation of the expression of $\arg F$, instead of direct gene deletion, was explored to balance L-ornithine production and cell growth. First, we chose an RBS optimization strategy, which is a promising metabolic engineering method that has been applied to construct a pathway for various compounds in previous reports (Sun et al. 2016; Veetil et al. 2017), to attenuate the expression of $\arg F$. However, replacement of the original RBS of $\arg F$ with sequences with low translation initiation intensity could not achieve the desired L-ornithine production, though cell growth was unaffected.

We speculate that deletion of ArgR inactivated the feedback inhibition of the transcription of the $\operatorname{argCJBDFR}$ operon in the $\mathrm{L}$-arginine biosynthetic pathway (Chen et al. 2014; Lee et al. 2011; Xu et al. 2013; Yim et al. 2011), which covered the attenuation effect of RBS optimization and A1G replacement and was unable to tightly control the metabolic flow of L-ornithine degradation. The transcription of $\arg F$ plays a more important role in L-ornithine catabolism. In view of this, to reduce the transcription level of argF, transcription terminators, which are known to play critical roles in regulating natural genetic systems and implementing synthetic genetic logic, are employed (Cambray et al. 2013). Interestingly, compared with the control strain with $\operatorname{argF}$ deletion, L-ornithine production titer was improved by $29.5 \%$ after insertion of the $r r n B$ terminator in front of $\arg F$. According to previous study, the terminators can not only stop the transcription process, but also function to prolong the mRNA half-life period, thus, stimulating the expression of upstream genes (Curran et al. 2013; Uzelac et al. 2015). Combined with analysis of transcriptional levels, we confirmed that inserting a terminator in front of $\operatorname{argF}$ causes high expression of the $\operatorname{argCJBD}$ gene cluster. Overexpression of the $\operatorname{argCJBD}$ operon is essential for L-ornithine biosynthesis (Hwang et al. 2008). In addition, independent overexpression of ArgJ in C. glutamicum 1006 $\triangle$ argR was reported to significantly improve L-ornithine fermentation (Hao et al. 2016). Therefore, the improvement of L-ornithine production was attributed to the activated expression of the upstream genes by the terminator. A similar conclusion had been drawn in a previous work, where integration of the transcription terminator downstream of the target genes caused a significant improvement of the expression level in a plasmid (Ito et al. 2015).

In conclusion, numerous efforts have been made to attenuate the expression of $\arg F$, at both the translation and transcription levels, with the aim to increase the production of L-ornithine. Those strategies with several advantages over the previous argF deletion can be employed to the existing strains to further improvement of L-ornithine production and may be widely applicable to fine turning the expression of other growth coupled enzymes. To our knowledge, this is the first study in which a terminator-based strategy has been successfully developed to reduce the expression of $\arg F$ and enhance L-ornithine production. The relative mRNA analysis provides valuable information for enhancing the expression of the upstream genes by insertion of terminator, which may find use in the construction of other middle metabolite producing strains. However, we failed to determine the optimal expression of $\arg F$ for L-ornithine production without cell growth disturbance, and the L-ornithine production titer achieved in this study was relatively lower than that reported by other studies (Kim et al. 2015). However, insertion of a developed terminator, as performed in this study, is a novel strategy for improving L-ornithine production, which has potential application in engineering other high L-ornithine strains. The successful application of a terminator to regulate upstream and downstream gene expression also hinted at the possible applications of terminators in metabolic engineering to produce valuable products, which would enrich the metabolic engineering strategies for selective strain development. In our recent work, this strategy was employed for development of even higher L-ornithine producing strains by attenuation of proB and $n c g l 2228$ Zhang et al. (2017). According to our experience, insertion of terminator is a convenient and easy method than gene deletion in the development of engineered C. glutamicum strains. We expect this technology to be extended to allow more laboratories to use it. In our next 
work, more experiments and examples based on terminators will be provided in the development of high L-ornithine producing strains.

\section{Additional file}

Additional file 1. Primers used in this study.

\section{Abbreviations}

RBS: ribosome bind site; OTC: ornithine carbamoyl transferase; RNAP: RNA polymerase; NAGK: N-acetyl-L-glutamate kinase.

\section{Authors' contributions}

BZ and MY planned and conducted the experiments, analyzed and interpreted data, and wrote the manuscript; $Y Z$ and $B C Y$ supervised the research and finalized the manuscript. All authors read and approved the final manuscript.

\section{Author details}

${ }^{1}$ Laboratory of Biosystems and Microanalysis, State Key Laboratory of Bioreactor Engineering, East China University of Science and Technology, Shanghai 200237, China. ${ }^{2}$ School of Chemistry and Chemical Engineering, Shihezi University, Xinjiang 832000, China.

\section{Acknowledgements}

We thank Dr. Andreas Burkovski and Dr. Xue-Lan Chen for providing pXMJ19 and pk18mobsacB. We thank Dr. Zhong-Gui Mao and Dr. Li-Ming Liu for providing strains Corynebacterium glutamicum S9114.

\section{Competing interests}

The authors declare that they have no competing interests.

\section{Availability of data and materials}

Gene sequences used in this project are from Genbank (http://www.ncbi.nlm. nih.gov/) and the material and data supporting their findings can be found in the main paper and the Additional file.

\section{Consent for publication}

Not applicable.

\section{Ethics approval and consent to participate}

This article does not contain any studies with human participants or animals performed by any of the authors.

\section{Funding}

This research was funded by National Science Foundation of China (31401592), the Fundamental Research Funds for the Central Universities (222201714051)

\section{Publisher's Note}

Springer Nature remains neutral with regard to jurisdictional claims in published maps and institutional affiliations.

Received: 30 January 2018 Accepted: 12 February 2018

Published online: 24 February 2018

\section{References}

Cambray G, Guimaraes JC, Mutalik VK, Lam C, Mai QA, Thimmaiah T, Carothers JM, Arkin AP, Endy D (2013) Measurement and modeling of intrinsic transcription terminators. Nucleic Acids Res 41(9):5139-5148. https://doi. org/10.1093/nar/gkt163

Chen YJ, Liu P, Nielsen AA, Brophy JA, Clancy K, Peterson T, Voigt CA (2013) Characterization of 582 natural and synthetic terminators and quantification of their design constraints. Nat Methods 10(7):659-664 https://doi.org/10.1038/nmeth.2515

Chen XL, Zhang B, Tang L, Jiao HT, Xu HY, Xu F, Xu H, Wei H, Xiong YH (2014) Expression and characterization of $\mathrm{ArgR}$, an arginine regulatory protein in Corynebacterium crenatum. Biomed Environ Sci 27(6):436-443. https:// doi.org/10.3967/bes2014.072

Chinard FP (1952) Photometric estimation of proline and ornithine. J Bio Chem 199:91-95

Curran KA, Karim AS, Gupta A, Alper HS (2013) Use of expression-enhancing terminators in Saccharomyces cerevisiae to increase mRNA half-life and improve gene expression control for metabolic engineering applications. Metab Eng 19:88-97. https://doi.org/10.1016/j.ymben.2013.07.001

Hao N, Mu J, Hu N, Xu S, Shen P, Yan M, Li Y, Xu L (2016) Implication of ornithine acetyltransferase activity on L-ornithine production in Corynebacterium glutamicum. Biotechnol Appl Biochem 63(1):15-21. https://doi. org/10.1002/bab.1353

Hwang GH, Cho JY (2014) Enhancement of L-ornithine production by disruption of three genes encoding putative oxidoreductases in Corynebacterium glutamicum. J Ind Microbiol Biotechnol 41(3):573-578. https://doi. org/10.1007/s10295-013-1398-8

Hwang JH, Hwang GH, Cho JY (2008) Effect of increased glutamate availability on L-ornithine production in Corynebacterium glutamicum. J Microbiol Biotechnol 18(4):704-710

Ito Y, Yamanishi M, Ikeuchi A, Matsuyama T (2015) A highly tunable system for the simultaneous expression of multiple enzymes in Saccharomyces cerevisiae. ACS Synth Biol 4(1):12-16. https://doi.org/10.1021/sb500096y

Jakoby M, Ngouoto-Nkili CE, Burkovski A (1999) Construction and application of new Corynebacterium glutamicum vectors. Biotechnol Tech 13(6):437441. https://doi.org/10.1023/A:1008968419217

Jensen JV, Eberhardt D, Wendisch VF (2015) Modular pathway engineering of Corynebacterium glutamicum for production of the glutamate-derived compounds ornithine, proline, putrescine, citrulline, and arginine. J Biotechnol 214:85-94. https://doi.org/10.1016/j.jbiotec.2015.09.017

Jiang LY, Chen SG, Zhang YY, Liu JZ (2013) Metabolic evolution of Corynebacterium glutamicum for increased production of L-ornithine. BMC Biotechnol 13:47. https://doi.org/10.1186/1472-6750-13-47

Kim SY, Lee J, Lee SY (2015) Metabolic engineering of Corynebacterium glutamicum for the production of L-ornithine. Biotechnol Bioeng 112(2):416421. https://doi.org/10.1002/bit.25440

Lee YJ, Cho JY (2006) Genetic manipulation of a primary metabolic pathway for L-ornithine production in Escherichia coli. Biotechnol Lett 28(22):18491856. https://doi.org/10.1007/s10529-006-9163-y

Lee SY, Cho JY, Lee HJ, Kim YH, Min J (2010) Enhancement of ornithine production in proline-supplemented Corynebacterium glutamicum by ornithine cyclodeaminase. J Microbiol Biotechnol 20(1):127-131

Lee SY, Park JM, Lee JH, Chang ST, Park JS, Kim YH, Min J (2011) Interaction of transcriptional repressor ArgR with transcriptional regulator FarR at the argB promoter region in Corynebacterium glutamicum. Appl Environ Microbiol 77(3):711-718. https://doi.org/10.1128/AEM.01610-10

Liao CH, Yao L, Xu Y, Liu WB, Zhou Y, Ye BC (2015) Nitrogen regulator GInR controls uptake and utilization of non-phosphotransferase-system carbon sources in actinomycetes. Proc Natl Acad Sci USA 112(51):15630-15635 https://doi.org/10.1073/pnas.1508465112

Man Z, Xu M, Rao Z, Guo J, Yang T, Zhang X, Xu Z (2016) Systems pathway engineering of Corynebacterium crenatum for improved L-arginine production. Sci Rep 6:28629. https://doi.org/10.1038/srep28629

Mei J, Xu N, Ye C, Liu L, Wu J (2016) Reconstruction and analysis of a genomescale metabolic network of Corynebacterium glutamicum S9114. Gene 575(2 Pt 3):615-622. https://doi.org/10.1016/j.gene.2015.09.038

Nakamura M, Suzuki A, Akada J, Tomiyoshi K, Hoshida H, Akada R (2015) End joining-mediated gene expression in mammalian cells using PCR-amplified DNA constructs that contain terminator in front of promoter. Mol Biotechnol 57(11-12):1018-1029. https://doi.org/10.1007/ s12033-015-9890-1

Niebisch A, Bott M (2001) Molecular analysis of the cytochrome bc 1-aa 3 branch of the Corynebacterium glutamicum respiratory chain containing an unusual diheme cytochrome c 1. Arch Microbiol 175(4):282-294. https://doi.org/10.1007/s002030100262

Schneider J, Eberhardt D, Wendisch VF (2012) Improving putrescine production by Corynebacterium glutamicum by fine-tuning ornithine 
transcarbamoylase activity using a plasmid addiction system. Appl Microbiol Biotechnol 95(1):169-178. https://doi.org/10.1007/ s00253-012-3956-9

Shen J, Chen J, Jensen PR, Solem C (2017) A novel genetic tool for metabolic optimization of Corynebacterium g/utamicum: efficient and repetitive chromosomal integration of synthetic promoter-driven expression libraries. Appl Microbiol Biotechnol 101(11):4737-4746. https://doi. org/10.1007/s00253-017-8222-8

Sun H, Zhao D, Xiong B, Zhang C, Bi C (2016) Engineering Corynebacterium glutamicum for violacein hyper production. Microb Cell Fact 15(1):148 https://doi.org/10.1186/s12934-016-0545-0

Tian T, Salis HM (2015) A predictive biophysical model of translational coupling to coordinate and control protein expression in bacterial operons. Nucleic Acids Res 43(14):7137-7151. https://doi.org/10.1093/nar/gkv635

Uzelac G, Miljkovic M, Lozo J, Radulovic Z, Tosic N, Kojic M (2015) Expression of bacteriocin $L s b B$ is dependent on a transcription terminator. Microbiol Res 179:45-53. https://doi.org/10.1016/j.micres.2015.06.011

Veetil VP, Angermayr SA, Hellingwerf KJ (2017) Ethylene production with engineered Synechocystis sp PCC 6803 strains. Microb Cell Fact 16(1):34. https://doi.org/10.1186/s12934-017-0645-5

Xu M, Rao Z, Dou W, Xu Z (2013) The role of ARGR repressor regulation on L-arginine production in Corynebacterium crenatum. Appl Biochem Biotechnol 170(3):587-597. https://doi.org/10.1007/s12010-013-0212-4
Yim SH, Jung S, Lee SK, Cheon Cl, Song E, Lee SS, Shin J, Lee MS (2011) Purification and characterization of an arginine regulatory protein, ArgR, in Corynebacterium glutamicum. J Ind Microbiol Biotechnol 38(12):19111920. https://doi.org/10.1007/s10295-011-0977-9

Zajac A, Poprzecki S, Zebrowska A, Chalimoniuk M, Langfort J (2010) Arginine and ornithine supplementation increases growth hormone and insulinlike growth factor-1 serum levels after heavy-resistance exercise in strength-trained athletes. J Strength Cond Res 24(4):1082-1090. https:// doi.org/10.1519/JSC.0b013e3181d321ff

Zhang B, Wan F, Qiu YL, Chen XL, Tang L, Chen JC, Xiong YH (2015) Increased $\mathrm{L}$-arginine production by site-directed mutagenesis of $\mathrm{N}$-acetyl-L-glutamate Kinase and proB Gene Deletion in Corynebacterium crenatum. Biomed Environ Sci 28(12):864-874. https://doi.org/10.3967/bes2015.120

Zhang B, Ren LQ, Yu M, Zhou Y, Ye BC (2017a) Enhanced L-ornithine production by systematic manipulation of $\mathbf{L}$-ornithine metabolism in engineered Corynebacterium glutamicum S9114. Bioresourc Technol 250:60-68. https://doi.org/10.1016/j.biortech.2017.11.017

Zhang B, Yu M, Zhou Y, Li Y, Ye BC (2017b) Systematic pathway engineering of Corynebacterium glutamicum 59114 for L-ornithine production. Microb Cell Fact 16(1):158. https://doi.org/10.1186/s12934-017-0776-8

\section{Submit your manuscript to a SpringerOpen ${ }^{\circ}$ journal and benefit from:}

- Convenient online submission

- Rigorous peer review

- Open access: articles freely available online

- High visibility within the field

- Retaining the copyright to your article

Submit your next manuscript at $\boldsymbol{\nabla}$ springeropen.com 